\title{
Ecstasy/MDMA attributed problems reported by novice, moderate and heavy recreational users
}

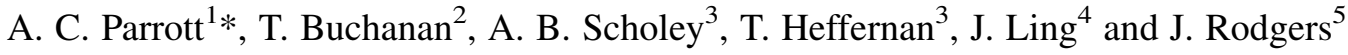 \\ ${ }^{1}$ Recreational Drugs Research Group, School of Psychology, University of East London, London E15 4LZ, UK \\ ${ }^{2}$ Department of Psychology, University of Westminster, London W1B $2 U W, U K$ \\ ${ }^{3}$ Human Cognitive Neuroscience Unit, Department of Psychology, University of Northumbria, \\ Newcastle-upon-Tyne NE1 8ST, UK \\ ${ }^{4}$ Psychology Section, University of Teeside, Middlesborough TS1 3BA, UK \\ ${ }^{5}$ Department of Clinical Psychology, University of Newcastle, Newcastle-upon-Tyne NE1 7RU, UK
}

Rationale The recreational use of MDMA/Ecstasy (3,4-methylenedioxymethamphetamine) is associated with many psychobiological problems, but there is a paucity of data on how these relate to the level of past use. Objectives: to assess the incidence of Ecstasy-attributed problems as reported by novice, moderate and heavy users. Methods: 763 unpaid volunteers took part in a WWW study of recreational drug use. This report is based on the 282 Ecstasy users from that sample, who comprised 109 novice users (1-9 occasions), 136 moderate users (10-99 occasions), and 36 heavy users ( +100 occasions). Yes/no responses were automatically recorded to a series of questions covering psychobiological problems experienced when drug-free, which were attributed by the respondents to their Ecstasy use. Results: Depression, memory problems, anxiety, mood fluctuation, poor concentration, infections, tremors/twitches and weight loss, were all significantly associated with the extent of Ecstasy use. Thus memory problems attributed to Ecstasy were reported by $19 \%$ of novice users, $52 \%$ of heavy users and $73 \%$ of heavy users (chi-square 42.74 , $\mathrm{df}=2, p<0.001$ ); many of the other variables showed similar trends. Conclusions The incidence of problems attributed to Ecstasy use, is directly related to the number of occasions it has been used. Copyright (C) 2002 John Wiley \& Sons, Ltd.

KEY WORDS - Ecstasy; MDMA; memory; mood; depression

\section{INTRODUCTION}

The recreational use of MDMA is associated with a wide range of psychobiological problems: memory deficits, raised psychiatric symptom profiles, altered patterns of eating, sleep and sex (McCann et al., 2000; Parrott, 2000, 2001). Most previous research has compared Ecstasy users with non-user controls (Rodgers, 2000; Heffernan et al., 2001; Morgan, 1999), although a few studies have directly compared light and heavy Ecstasy users. Two investigations found no significant cognitive performance differences between novice and regular users (Parrott et al., 1998; Parrott and Lasky, 1998), although Fox

* Correspondence to: Professor A. C. Parrott, School of Psychology, University of East London, London E15 4LZ, UK. Tel: 0208 2234505. E-mail: a.c.parrott@uel.ac.uk et al. (2001) found a significant association between past Ecstasy usage and the extent of cognitive deficits on two tasks. Schifano et al. (1998) reported that Ecstasy users with psychopathological problems (e.g. depression, bulimia, impulse control disorder) had taken the drug on significantly more occasions than the non-problematic users. Parrott et al. (2000) found the highest psychiatric symptom scores in heavy Ecstasy users, while the symptom profiles for moderate users were closer to those for the non-user controls. Disorders of eating/appetite, sleep and sexual interest/pleasure have also been reported (Parrott et al., 2001; Schifano et al., 1998; Topp et al., 1999), but there are little data on their occurrence in novice versus more experienced users. The aim of the current study was to compare the incidence of problems attributed to Ecstasy use, reported by novice, moderate and heavy users. 


\section{MATERIALS AND METHODS}

\section{General procedures and participant characteristics}

This report is based upon a WWW study into the selfrated memory abilities of young recreational drug users and non-users. The data were acquired through a web-site hosted on the University of Westminster web server and accessible via a number of different addresses (e.g. www.drugresearch.org.uk). The participants were recruited through a variety of techniques, such as announcements to students at colleges and universities, and recruitment notices posted on relevant Internet sites. Each unpaid volunteer completed a number of demographic items and questionnaires related to their memory abilities and past drug use. An initial report on the memory questionnaire findings from the preliminary cohort has already been published (Rodgers et al., 2001); this is being followed by a final report on the overall memory questionnaire findings from the total sample of 763 participants (Rodgers et al., submitted).

Each unpaid volunteer completed a modified version of the University of East London (UEL) Recreational Drug Use Questionnaire (Parrott et al., 2000) to indicate their past drug experience. For Ecstasy/ MDMA the five response choices were: "never in my life', '1-9 occasions', '10-99 occasions', 'more than 100 occasions' and 'prefer not to answer'. All participants chose to answer the question, with most $(n=481)$ indicating that they had never used Ecstasy. The current report is based solely on the 282 Ecstasy users, who comprised: 109 novice users (1-9 occasions), 136 moderate users (10-99 occasions) and 37 heavy users $(+100$ occasions). The Ecstasy users also indicated their normal MDMA dose per occasion, and the highest number of tablets ever taken in one week, both of which differed significantly across subgroups. Thus $100 \%$ of novice users normally took $1-2$ tablets per occasion, compared with $84 \%$ of moderate users and $62 \%$ of heavy users; a normal dose of 3-4 tablets/occasion was reported by $0 \%$ of novice users, $13 \%$ of moderate users and $24 \%$ of heavy users; while a normal dose of +4 tablets/occasion was reported by $0 \%$ of novice users, $3 \%$ of moderate users and $14 \%$ of heavy users (chi-square 39.40, $\mathrm{df}=4, p<0.001$ ). With reference to the most tablets ever taken in one week, a maximum of 1-2 tablets/week was reported by $91 \%$ of novice users, $23 \%$ of moderate users and $0 \%$ of heavy users; a maximum of 3-9 tablets/week was reported by $9 \%$ of novice users, $68 \%$ of moderate users and $65 \%$ of heavy users; while a maximum of +10 tablets/week was reported by $0 \%$ of novice users, $9 \%$ of moderate users and $35 \%$ of heavy users (chi-square 169.99, df $=4, p<0.001$; see Scholey et al., submitted).

\section{Assessment measures}

Each participant was asked to indicate whether or not they had experienced any of a list of 11 problems while 'off-drug' which they attributed to their Ecstasy use. The questions were based upon the literature on psychobiological problems in Ecstasy users, and covered cognitive deficits (poor memory, poor concentration), mood changes (depression, anxiety, mood fluctuation, impulsivity) and physiological/medical disorders (weight loss, infections, tremors/twitches, poor sleep, sexual problems). Each question required a binary yes/no response.

\section{Data analysis}

The data were analysed by $2 \times 3$ chi-square, with two levels of response (yes/no) and three drug usage categories (novice, moderate and heavy).

\section{RESULTS}

The percentage of novice, moderate and heavy recreational Ecstasy/MDMA users (1-9, 10-99 and +100 occasions) reporting problems which they attributed to the use of Ecstasy are shown in Table 1. This table

Table 1. Novice, moderate, and heavy recreational Ecstasy/ MDMA drug users (1-9, 10-99 and +100 occasions). Percentage of each group reporting problems when drug-free, which they attribute to the use of Ecstasy

\begin{tabular}{lcccc}
\hline $\begin{array}{l}\text { Ecstasy/MDMA } \\
\text { user group }\end{array}$ & Novice & Moderate & Heavy & Chi-square \\
\hline Ecstasy usage (occasions) & $1-9$ & $10-99$ & +100 \\
Sample size ( $n)$ & 109 & 136 & 37 \\
Mood and cognitive problems attributed to Ecstasy use \\
Depression & $33 \%$ & $54 \%$ & $65 \%$ & $16.23^{\mathrm{a}}$ \\
Mood fluctuation & $38 \%$ & $70 \%$ & $80 \%$ & $31.21^{\mathrm{a}}$ \\
Impulsivity & $18 \%$ & $26 \%$ & $32 \%$ & $3.79 \mathrm{~ns}$ \\
Anxiety & $32 \%$ & $40 \%$ & $60 \%$ & $9.37^{\mathrm{b}}$ \\
Poor concentration & $32 \%$ & $62 \%$ & $70 \%$ & $29.80^{\mathrm{a}}$ \\
Memory problems & $19 \%$ & $52 \%$ & $73 \%$ & $42.74^{\mathrm{a}}$ \\
Physiological and medical problems attributed to Ecstasy use \\
Weight loss & $10 \%$ & $37 \%$ & $48 \%$ & $28.99^{\mathrm{a}}$ \\
Infections & $5 \%$ & $9 \%$ & $35 \%$ & $24.94^{\mathrm{a}}$ \\
Tremors/twitches & $14 \%$ & $20 \%$ & $38 \%$ & $9.95^{\mathrm{b}}$ \\
Poor sleep & $37 \%$ & $41 \%$ & $52 \%$ & $2.15 \mathrm{~ns}$ \\
Sexual problems & $7 \%$ & $11 \%$ & $22 \%$ & $3.94 \mathrm{~ns}$ \\
\hline
\end{tabular}

$2 \times 3$ chi-square analyses $(\mathrm{df}=2$; two-tailed $))$ were performed on the yes/no responses from the three groups. ${ }^{\mathrm{a}}=p<0.001$; ${ }^{\mathrm{b}}=p<0.01, \mathrm{~ns}$, non-significant. 
also presents the chi-square values for the binary responses from the three usage groups.

\section{DISCUSSION}

Memory problems were strongly associated with past Ecstasy usage (Table 1), since they were reported by $19 \%$ of novice users, $52 \%$ of moderate users and $73 \%$ of heavy users (chi-square $=42.76, \mathrm{df}=2, p<0.001$ ). This is consistent with the extensive literature on memory disorders in Ecstasy users, with significant deficits found across a wide range of performance tasks and questionnaires (Gouzoulis-Meyfrank et al., 2000; Heffernan et al., 2001; Morgan, 1999, 2000; Parrott and Lasky, 1998; Parrott et al., 1998; Parrott, 2001; Rodgers, 2000; Rodgers et al., 2001). The findings are also consistent with Fox et al. (2001), who found that spatial recall was inversely related to past Ecstasy usage, and that verbal recognition was also worst in the heavy users. The data also show that many Ecstasy users are fully aware of their memory difficulties. Depression, anxiety and mood fluctuations attributed to Ecstasy, were also strongly related to the number of occasions it had been used; they were reported by $60 \%-80 \%$ of heavy users, $54 \%-70 \%$ of moderate users and $32 \%-38 \%$ of novice users (Table 1). Curran and Travill (1997) reported 'midweek blues' in weekend Ecstasy users, with some individuals reporting clinically borderline levels of depression in the days following MDMA. Parrott and Lasky (1998) noted considerable mood fluctuation over the week when Ecstasy was taken, with high moods on-drug followed by sadness and unsociability in the days afterwards, due probably to monoaminergic depletion (Parrott, 2001). Depression is, however, not just a rebound phenomenon, but is also reported by former users 'now leading relatively drugfree lives' (MacInnes et al., 2001, p. 181).

Other studies have reported raised psychiatric symptom profiles in recreational Ecstasy polydrug users (Schifano et al., 1998; Parrott et al., 2000, 2001). Topp et al. (1999, p. 112) found a range of psychobiological, occupational and medical complaints in regular users: 'On average, subjects reported eight physical and four psychological side-effects which they perceived as being due, at least in part, to their use of Ecstasy'. The current findings confirm the diversity of problems experienced by heavy Ecstasy users, including weight loss, tremors/twitches and infections (Table 1). Although reported by a significantly higher proportion of heavy users, they were also occasionally noted by novice users. This may reflect differences in individual sensitivity, with some individuals reporting adverse reactions despite having taken the drug just a few times. Three variables were not significantly related to past usage: impulsivity, poor sleep and sexual problems, although the pattern of reported problems did conform to the same trend (Table 1). Many regular clubbers display irregular patterns of rest and sleep, thus it was not surprising that poor sleep was reported by all groups. McCann et al. (2000) noted that the sleep architecture of abstinent Ecstasy users often varied from those of non-users, although sometimes in contrasting ways. Similarly while some MDMA users report acute difficulties in sexual activity, others report acute sexual enhancement (Zemishlany et al., 2001). However, a minority of regular Ecstasy users report long-term reductions in sexual interest and/or ability. Topp et al. (1999) found that $12 \%$ of regular users reported 'loss of sex urge' during the last 6 months. Parrott et al. (2001) found that $14 \%$ of heavy users complained of 'loss of sexual interest or pleasure'.

There are several limitations to the current study which are characteristic of all recreational Ecstasy drug research. Thus there was no control over which drugs people had taken, nor the degree to which 'Ecstasy' tablets were MDMA or other dance drugs. Regular clubbers often display irregular circadian rhythms, with prolonged periods of dancing, disrupted sleep, inadequate rest and poor nutrition. All these factors may affect their health, and general well-being (Parrott et al., 2001). For a fuller discussion of these issues the reader is referred to Curran (2000), while they are also discussed in the following reviews: Morgan (2000), Schifano (2000) and Parrott (2000, 2001). Heavy Ecstasy users often take a variety of psychoactive drugs, not only illicit compounds such as amphetamine, cocaine or LSD, but also legal drugs such as alcohol and nicotine (Parrott et al., 2001). The drug usage patterns from the current data set confirms that many of our Ecstasy users were illicit polydrug users (Scholey et al., submitted). Thus there were many potentially confounding factors, although it must be emphasized that the current data are of attributions given to Ecstasy by the users themselves. Further research is needed to investigate how they attribute their problems to other psychoactive drugs, or to related factors.

In conclusion, the current findings demonstrate that self-reported psychobiological problems attributed to Ecstasy, were a direct function of the amount of times it has been taken. A high proportion of the heavy users complained of problems, but they were also reported by substantial numbers of moderate users, and a smaller proportion of novice users 
(Table 1). It should be noted that the more experienced users also tended to take more tablets on each occasion, and reported higher maximum consumption rates (Scholey et al., submitted). The nature of these problems was consistent with previous findings (McCann et al., 2000; Morgan, 2000; Parrott, 2000, 2001; Rodgers et al., 2001; Schifano et al., 1998; Topp et al., 1999). Some of them may reflect rebound or 'come-down' effects, although others may well result from longer-term serotonergic neurodegeneration (McCann et al., 2000; Ricaurte et al., 2000; Reneman et al., 2001). One topic for future research is to compare users who complain of drug-related problems, with those who do not (Fox et al., 2001). It may be that the absence of problems reflects a robust serotonergic system, a neuroprotective pattern of usage (e.g. avoidance of hyperthermia), or an atypical drug metabolism. Alternatively it may reflect poor selfawareness, and/or a lack of recognition of the problems associated with chronic MDMA use.

\section{REFERENCES}

Curran HV. 2000. Is MDMA (Ecstasy) neurotoxic in humans? an overview of evidence and of methodological problems in research. Neuropsychobiology 42: 34-41.

Curran HV, Travill RA. 1997. Mood and cognitive effects of 3,4methylenedioxymethamphetamine (MDMA, 'Ecstasy'): weekend 'high' followed by mid-week 'low'. Addiction 92: 821-831.

Fox H, Parrott AC, Turner JJD. 2001. Ecstasy/MDMA related cognitive deficits: a function of dosage rather than awareness of problems. J Psychopharmacol 15: 273-281.

Gouzoulis-Meyfrank E, Daumann J, Tuchtenhagen F, et al. 2000. Impaired cognitive performance in drug free users of recreational Ecstasy (MDMA). J Neurol Neurosurg Psychiat 68: 719-725.

Hefferman TM, Ling J, Scholey AB. 2001. Subjective ratings of prospective memory deficits in MDMA ('Ecstasy') users. Hum Psychopharmacol 16: 339-344.

MacInnes N, Handley SL, Harding GFA. 2001. Former chronic methylenedioxymethamphetamine (MDMA or Ecstasy) users report mild depressive symptoms. J Psychopharmacol 15: 181186.

McCann UD, Eligulashvili V, Ricaurte GA. 2000. (+ - ) 3,4methylenedioxymethamphetamine ('Ecstasy')—induced serotonin neurotoxicity: clinical studies. Neuropsychobiology 42: $11-16$.

Morgan MJ. 1999. Memory deficits associated with recreational use of 'Ecstasy' (MDMA). Psychopharmacology 141: 30-36.
Morgan MJ. 2000. Ecstasy (MDMA): a review of its possible persistent psychological effects. Psychopharmacology 152: 230-248.

Parrott AC. 2000. Human research on MDMA (3,4-methylenedioxymethamphetamine) neurotoxicity: cognitive an behavioral indices of change. Neuropsychobiology 42: 17-24.

Parrott AC. 2001. Human psychopharmacology of Ecstasy (MDMA): a review of 15 years of empirical research. Hum Psychopharmacology 16: 557-577.

Parrott AC, Lasky J. 1998. Ecstasy (MDMA) effects upon mood and cognition; before, during, and after a Saturday night dance. Psychopharmacology 139: 261-268.

Parrott AC, Lees A, Garnham NJ, Jones M, Wesnes K. 1998. Cognitive performance in recreational users of MDMA or 'Ecstasy': evidence for memory deficits. J Psychopharmacol 12: 79-83.

Parrott AC, Milani R, Parmar R, Turner JJD. 2001. Ecstasy polydrug users and other recreational drug users in Britain and Italy: psychiatric symptoms and psychobiological problems. Psychopharmacology 159: 77-82.

Parrott AC, Sisk E, Turner J. 2000. Psychobiological problems in heavy 'Ecstasy' (MDMA) polydrug users. Drug Alcohol Depend 60: $105-110$.

Reneman L, Booij J, Majoie CBL, van den Brink W, den Heeten GJ. 2001. Investigating the potential neurotoxicity of Ecstasy (MDMA): an imaging approach. Hum Psychopharmacol 16: 579-588.

Rodgers J. 2000. Cognitive performance amongst recreational users of 'Ecstasy'. Psychopharmacology 151: 19-24.

Rodgers J, Buchanan T, Scholey AB, Heffernan TM, Ling J, Parrott A. 2001. Differential effects of Ecstasy and cannabis on self reports of memory ability: a web-based study. Hum Psychopharmacol 16: 619-625.

Rodgers J, Buchanan T, Scholey AB, Heffernan TM, Ling J, Parrott AC. Self reports of memory ability amongst recreational drug users: a web based study. Submitted.

Schifano F. 2000. Potential neurotoxicity of MDMA (Ecstasy): subjective self-reports, evidence from an Italian drug addiction center and clinical case studies. Neuropsychobiology $\mathbf{4 2}$ : 25-33.

Schifano F, Di Furia L, Forza G, Minicuci N, Bricolo R. 1998. MDMA ('Ecstasy') consumption in the context of polydrug abuse: a report on 150 patients. Drug Alcohol Depend 52: 85-90.

Scholey AB, Parrott AC, Buchanan T, Heffernan TM, Ling J, Rodgers J. Increased intensity of Ecstasy and polydrug usage in the more experienced recreational Ecstasy/MDMA users: a www study. Submitted.

Topp L, Hando J, Dillon P, Roche A, Solowij N. 1999. Ecstasy use in Australia: patterns of use and associated harm. Drug Alcohol Depend 55: 105-115.

Zemishlany Z, Aizenberg D, Weizman A. 2001. Subjective effects of MDMA ('Ecstasy') on human sexual function. Eur Psychiatry 16: $127-130$. 